\title{
Subsídios para uma política de gestão da informação da Embrapa Solos: à luz do regime de informação
}

\section{Claudia Regina Delaia}

\author{
Mestre em Ciência da Informação pelo Instituto \\ Brasileiro de Informação em Ciência e Tecnologia \\ - Convência IBICT/UFF (2008). Bibliotecária - \\ Embrapa Solos.
}

Isa Maria Freire

\begin{abstract}
Graduada em Ciências Sociais, com mestrado e doutorado em Ciência da Informação. Professora no Departamento e no Programa de Pós- Editora da revista Informação e Sociedade: Estudos e editora chefe da revista Pesquisa Brasileira em Ciência da Informação e Biblioteconomia.
\end{abstract}

Trata-se de pesquisa para subsidiar a formulação de uma Política de Gestão da Informação em Ciência e Tecnologia, com base no conceito do regime de informação, em uma instituição de pesquisa. Esta pesquisa teve como metodologia a aplicação de um estudo de usuários, analisando o uso de fontes de informação para a produção científica e, posteriormente, a identificação $e$ caracterização do regime de informação na instituição. $A$ partir dos resultados desta pesquisa, foram produzidos $e$ definidos esquemas e fluxogramas para subsidiar a formulação de uma Política de Gestão da Informação em Instituições de Pesquisa, segundo os conceitos do regime de informação.

Palavras-chave: Política de Informação; Gestão da Informação; Regime de Informação; Estudos de Usuários; Técnica do Incidente Crítico; Embrapa Solos. 


\title{
Subsidies to a policy information management of Embrapa Soil based on regime of information
}

\begin{abstract}
Refers on a research to reinforce information resource management policy in Science and Technology based on information regime concept for a Research Institution. The methodology used was application of users study, analyzing the use of information sources for scientific production and, afterward, the identification and characterization of the regime of information in the Research Institution. From that point on schemes and fluxograms were defined and produced to subsidize the formulation from information resource management policy in Research Institution, concerning regimes of information concepts.
\end{abstract}

Keywords: Information policy; Information management; Regime of information; Critical incident technique; Users studies; Embrapa Solos.

Recebido em 21.10.2009 Aceito em 18.10.2010

\section{Introdução}

$\mathrm{Na}$ Sociedade da Informação, o fenômeno "Informação" assume dimensões e, em alguns casos, determina a forma como os segmentos da sociedade se organizam e se inter-relacionam. É necessário que sejam estabelecidas regras para que tais segmentos administrem seus recursos de forma harmônica, a fim de atender seu público. O estabelecimento de Políticas de Informação é determinante para uma sociedade, principalmente quando se refere ao Governo (Federal, Estadual, Municipal) e às instituições de pesquisa científica e tecnológica.

Com a globalização, o avanço tecnológico e o crescente fluxo de informação, a forma de acompanhamento e absorção desse grande volume de informação e das tecnologias tem sido cada vez mais discutida entre os cientistas e instituições.

em 1999, gonzález de gómez (1999a, p. 2) sugeriu uma intercessão entre política e gestão da informação, onde esta última é apresentada como "uma mediação lógica e imprescindível do uso decisório e estratégico da informação no contexto das políticas governamentais". esta intercessão ratificaria que os estudos da ciência da informação são interdisciplinares, relacionando diferentes abordagens sobre esse campo 
científico. deparamo-nos com a informação como ponto central entre política e gestão.

O objetivo da pesquisa foi contribuir para a discussão e formulação de uma Política de Gestão da Informação na Embrapa Solos, à luz do conceito de Regime de Informação.

\section{2 À luz do regime de informação}

O conceito de Regime de Informação realça componentes que contribuem para a compreensão de uma Política de Informação e para relações das e entre comunidades e instituições no que tange às ações de informação. Segundo González de Gómez (1999c), o conceito de regime de informação recorta para as esferas governantes das Empresas as ações e os recursos, além de toda complexidade que envolve a informação em uma sociedade contemporânea.

O conceito de Regime de Informação foi desenvolvido por Frohmann (1995, p. 4) e consiste em um conjunto de redes onde as informações são transferidas de seus produtores, por canais determinados, com a mediação de estruturas organizacionais às comunidades específicas ou aos consumidores.

Já para Braman (2004), a teoria de um regime global de informação propicia visão abrangente da política de informação em relação às instituições, as regras e normas frente à prática da política.

Nesta pesquisa, apoiamo-nos na definição de González de Gómez (2002) que, sob a concepção de "dispositivo"1 de Michel Foucault, define regime de informação como:

Um modo de produção informacional dominante numa formação social, conforme o qual serão definidos sujeitos, instituições, regras e autoridades informacionais, os meios e os recursos preferenciais de informação, os padrões de excelência e os arranjos organizacionais de seu processamento seletivo, seus dispositivos de preservação e distribuição (GONZÁLEZ DE GÓMEZ, 2002, p. 34).

Sob este prisma, um Regime de Informação pode ser visto como:

Um conjunto mais ou menos estável de redes sociocomunicacionais formais e informais nas quais informações podem ser geradas, organizadas e transferidas de diferentes produtores, através de muitos e diversos meios, canais e organizações, a diferentes destinatários ou receptores, sejam estes usuários específicos ou públicos amplos. [...] assim, está configurado, em cada caso, por

\footnotetext{
${ }^{1}$ Segundo Foucault (1995 apud WILKE; JARDIM, 2006), o dispositivo de informação abrange um conjunto variado de discursos, instituições, organizações arquitetônicas, decisões regulamentares, leis, medidas administrativas, enunciados científicos, filosóficos, morais, filantrópicos, produções artísticas.
} 
plexos de relações plurais e diversas: intermediáticas; interorganizacionais e intersociais. [Sendo constituído assim,] pela figura combinatória de uma relação de forças, definindo uma direção e arranjo de mediações comunicacionais e informacionais dentro de um domínio funcional (saúde, educação, previdência, etc.), territorial (município, região, grupo de países) ou de sua combinação. (GONZÁLEZ DE GÓMEZ, 1999b, p. 24; 2002, p. 34).

Também são constituintes de um regime de informação:

- Dispositivos de informação - mecanismo operacional ou conjunto de meios ou, ainda, como González de Gómez (1996, p. 63) exemplifica, "um conjunto de produtos e serviços de informação e das ações de transferência de informação".

- Atores sociais - "reconhecidos por suas formas de vidas e constroem suas identidades através de ações formativas existindo algum grau de institucionalização e estruturação das ações de informação" (COLLINS; KUSH, 1999 apud GONZÁLEZ DE GÓMEZ, 2003, p. 35).

- Artefatos de informação - modos tecnológicos e materiais de armazenagem, processamento e de transmissão de dados; poderiam ser, nos dias de hoje, as bibliotecas digitais e os portais da web. (GONZÁLEZ DE GÓMEZ, 2002, 2003).

O QUADRO 1, a seguir, demonstra a constituição de uma ação de informação no Regime de Informação e as relações entre os meios e os fins, conforme González de Gómez (2003).

QUADRO 1

Modalidades, sujeitos e teleologia das ações de informação

\begin{tabular}{l|l|l|l}
\hline \multicolumn{1}{c|}{$\begin{array}{c}\text { Ações de } \\
\text { Informação }\end{array}$} & \multicolumn{1}{c|}{ Atores } & \multicolumn{1}{c}{ Atividades } & \multicolumn{1}{c}{ Para } \\
\hline \hline Ação de Mediação & $\begin{array}{l}\text { Sujeitos Sociais } \\
\text { Funcionais (práxis) }\end{array}$ & $\begin{array}{l}\text { Atividades Sociais } \\
\text { Múltiplas }\end{array}$ & $\begin{array}{l}\text { Transformar o mundo } \\
\text { social ou natural }\end{array}$ \\
\hline $\begin{array}{l}\text { Ação Formativa ou } \\
\text { Finalista }\end{array}$ & $\begin{array}{l}\text { Sujeitos Sociais } \\
\text { Experimentadores } \\
\text { (poiesis) }\end{array}$ & $\begin{array}{l}\text { Atividades } \\
\text { Heurísticas e de } \\
\text { Inovação }\end{array}$ & $\begin{array}{l}\text { Transformar o } \\
\text { conhecimento para } \\
\text { transformar o mundo }\end{array}$ \\
\hline $\begin{array}{l}\text { Ação Relacional } \\
\text { Inter-Meta-Pós- } \\
\text { mediática }\end{array}$ & $\begin{array}{l}\text { Sujeitos Sociais } \\
\text { Articuladores e } \\
\text { Reflexivos (legein) }\end{array}$ & $\begin{array}{l}\text { Atividades Sociais } \\
\text { de Monitoramento, } \\
\text { Controle e } \\
\text { Coordenação. }\end{array}$ & $\begin{array}{l}\text { Transformar a } \\
\text { informação e a } \\
\text { comunicação que } \\
\text { orientam o agir coletivo }\end{array}$ \\
\hline
\end{tabular}

Fonte: Adaptado de González de Gómez (2003, p. 37).

González de Gómez (2003, p. 37) sintetiza: "toda ação de informação tem uma orientação afim, mas só num caso essa finalidade é a geração de informação como potência e competência de transformação - nela mesma". 
Tendo como base as categorias de Collins e Kush (1999) citadas por González de Gómez (2003, p. 36), considerando-se um contexto, entende-se por ação de informação:

- De mediação, quando [...] fica atrelada aos fins e orientação de outra ação;

- Formativa, aquela que é orientada à informação não como meio, mas como sua finalização;

- Relacional, quando tem por finalidade intervir em outra ação de informação, de modo que - ainda quando de autonomia relativa - dela obtém a direção e fins.

Ainda são poucos os estudos que tratam de uma visão do todo no campo da Ciência da Informação. Portanto, a mediação apontada por González de Gómez (1999b, p. 78), no artigo que trata "da Política de informação ao papel da informação na política contemporânea", reforça o estudo sobre Política e Gestão de um Regime de Informação.

\section{Uma visão de gestão e políticas de informação}

Em uma sociedade em que informação, conhecimento, criatividade e inovação são primordiais, paulatinamente, são lançados desafios à comunidade científica. A informação é um ponto central entre Política e Gestão no ambiente governamental, institucional ou virtual, considerando as iniciativas em prol ao acesso livre à informação e ao uso de softwares livres.

Portanto, "gerir a informação" é uma das preocupações e desafios que transparecem nos artigos científicos na área da Ciência da Informação e em outras áreas do conhecimento. Uma definição bastante citada é a da pesquisadora Regina Cianconi, que em linhas gerais se assemelha às outras definições disponíveis. No entanto, a autora detalha em seu artigo os aspectos que contemplam a informação considerando o processo da Gestão (planejamento, seleção, coleta, análise, organização, otimização dos fluxos, normalização, disponibilização para uso e avaliação). (CIANCONI, 1999, p. 33).

Outros conhecidos autores, como McGee e Prussak ${ }^{2}$ (1994) e Davenport $^{3}$, (1998) referem-se à Gestão da Informação como o processo para identificar as necessidades de informação: coletar, classificar, armazenar, tratar e disponibilizar. Ressalta-se que esses autores atuam no segmento empresarial, isto é, consideram a informação para negócios.

Esta pesquisa teve como base o conceito de Gestão da Informação, sob o enfoque da Ciência da Informação, definido pelo Institute of Information Scientists (2001) também citado por Marchiori (2002, p. 75),

\footnotetext{
2 James MacGee e Laurence Prussak são membros fundadores do Ernst \& Young's Center for Information Technology and Strategy, empresa que assessora o segmento empresarial.

3 Thomas H. Davenport é professor titular de sistemas de informações gerenciais da School of Management da Boston University e diretor da Arthur Andersen Consulting Institute for Strategic Change.
} 
em que são contempladas não só as etapas da Gestão, mas também são destacadas as tecnologias, os indivíduos e os procedimentos, a saber:

[Gestão] que em sua essência [,] se ocupa do estudo da informação em si, isto é, a teoria e a prática que envolve [sic] sua criação, identificação, coleta, validação, representação, recuperação e uso, tendo como princípio o fato de que existe um produtor/consumidor de informação que busca, nesta, um "sentido" e uma "finalidade" [...].

[...] Neste contexto, tanto os processos administrativos, como a utilização de tecnologias são mecanismos facilitadores para otimização de processos que levam, idealmente, à comunicação efetiva da informação entre indivíduos e grupos. Assim, a gestão da informação tem, por princípio, enfocar o indivíduo (grupos ou instituições) e suas "situações-problema" no âmbito de diferentes fluxos de informação, os quais necessitam de soluções criativas e custo/efetivas [...].

O termo "gestão da informação" surge nos anos oitenta, nos Estados Unidos e na Inglaterra, como Gerência dos Recursos Informacionais, com foco em gerenciar a informação como recurso estratégico, tendo como marco a publicação do documento US Public Act A130 pelo Governo dos Estados Unidos ${ }^{4}$ (CIANCONI, 1999).

A amplitude e o potencial da Gestão da informação reforçam ainda mais a necessidade de pesquisas dos processos e recursos que tratam da Informação. Na Ciência da Informação, tendo em vista a sua interdisciplinaridade, encontramos fundamentos e técnicas que subsidiam a compreensão da informação em todo processo da Gestão.

E Marchiori (2002, p. 75-77), em seu artigo - A Ciência e a Gestão da Informação: Compatibilidades no Espaço Profissional - destaca os conhecimentos e contextos que envolvem o processo integral de Gestão dos recursos de informação nas organizações, assim descritos:

a) Planejamento: ações que vão desde a identificação das necessidades até a geração de produtos e serviços;

b) Comunicação: teorias e modelos de aplicação;

c) Gerência da informação e sistemas de controle: métodos de monitoramento do fluxo e tecnologias que apoiem o fluxo;

d) Gerência de recursos humanos: perfil e atividades dos atores no processo de gestão;

e) Gerência de recursos financeiros: da previsão à execução do orçamento;

f) Promoção, vendas e marketing: análise do ambiente externo em prol do produto ou serviço;

\footnotetext{
${ }^{4}$ Disponível em: <http://www.whitehouse.gov/omb/circulars/a130/a130trans4.htm>. Acesso em: 26 mar. 2008.
} 
g) Contexto político, ético, social e legal: situações políticas que englobam atividades humanas em geral, governo e informação em particular, abrangendo questões éticas e legais e temas correlatos;

h) Sistemas computacionais: processos no desenvolvimento de hardware e softwares;

i) Telecomunicações: questões de acesso e conectividade;

j) Aplicações da tecnologia da informação: coleta, armazenagem e recuperação da informação, videotexto, telex, reconhecimento de voz, digitalização, tecnologias de discos compactos, telecomunicações, métodos de publicação eletrônica e de disseminação de documentos via redes;

k) Meio ambiente: princípios de ergonomia, proteção de dados, copyright, pirataria, criptografia etcA autora relaciona outras áreas aplicáveis ao contexto da Gestão da Informação, como:

a) Metodologia da pesquisa: métodos de investigação, coleta de dados, amostragem, análises estatísticas, avaliação de resultados e produção de relatórios;

b) Linguística: conhecimentos da linguagem natural e formal das classificações;

c) Línguas estrangeiras: recurso para análise de fontes de informação, comunicação em um mundo conectado de maneira a oferecer serviços de tradução e resumos.Assim como diferentes áreas do conhecimento apresentam práticas e comportamentos peculiares, incluindo os respectivos cientistas (ZIMAN, 1979), a natureza da informação proveniente dessas mesmas áreas traz características inerentes à sua origem e aos usuários a que se destinam. E Saracevic alerta para a importância da "[...] integração e inter-relação entre produtores de conhecimentos, instituições de um modo geral, bibliotecas e serviços de informação, seus mecanismos e usuários [...]" (SARACEVIC, 1996, p. 58).

Na Sociedade da Informação, o fenômeno "Informação" determina a forma como os segmentos da sociedade se organizam e se interrelacionam. É necessário que sejam estabelecidas regras, para que tais segmentos administrem seus recursos de forma harmônica, a fim de atender o seu público.

Segundo a definição de Ferreira (1993, p. 430), política é "o conjunto dos fenômenos e das práticas relativos ao Estado ou a uma sociedade". A abrangência de uma Política em qualquer nível da sociedade demonstra sua amplitude e interferência no modo pelo qual as pessoas convivem e interagem com seus pares.

Para González de Gómez (1999a), os processos percorridos na Gestão da Informação são imprescindíveis no uso decisório e estratégico da informação, no contexto das políticas governamentais, bem como no contexto das organizações econômico-empresariais e sociais.

Tendo em vista que a pesquisa foi realizada no âmbito de uma instituição de pesquisa vinculada ao Governo Federal, baseamo-nos no conceito apresentado no documento "Contribuições para uma Política de 
ICT", que define Política de Informação em Ciência e Tecnologia (ICT) como:

Um conjunto de princípios e escolhas que definem o que seria desejável e realizável para um país como orientação de seus modos de geração, uso e absorção de ICT, através de diferentes procedimentos de promoção, regulação, coordenação e articulação, em interação com aquelas condições resultantes das políticas, práticas e contextos da produção de ciência, tecnologia e inovação (CTI) e das formas socialmente estabelecidas de sua apropriação (GONZÁLEZ DE GÓMEZ; CANONGIA, 2001, p. 11).

No decorrer de décadas passadas, pensamentos, eventos, personalidades e ações vieram fomentando a intenção do que seria uma Política de Informação, bem como a sua importância mundial. Assim, destacamos a fundação, por Paul Otlet e Henri La Fontaine, do Instituto Internacional de Bibliografia (atual Federação Internacional de Informação e Documentação) e da Liga das Nações e da Organização para a Cooperação Internacional, precursora da UNESCO (PEREIRA, 2000), tendo esta última um papel de destaque dentre as primeiras ações do governo para o estabelecimento de políticas públicas.

A Política de Informação emerge em um cenário pós-guerra (1950), onde se tem o Estado como responsável pela promoção da pesquisa e a ciência e tecnologia como campo de aplicação. De acordo com o documento Weinberg Report, o alcance e o escopo de uma política referem-se à "transferência de informação científica sob a responsabilidade do governo" (U.S. President's Science and Advisory Commitee, 1963 apud GONZÁLEZ DE GÓMEZ, 2002, p. 28).

Para a Organização das Nações Unidas para a Educação, Ciência e Cultura (UNESCO), as ações de uma política deveriam ser direcionadas ao estabelecimento de "um programa intergovernamental e cooperativo para promover e otimizar o acesso e uso da informação buscando superar as brechas científico-informacionais entre países centrais e periféricos". (JARDIM, 1995 apud GONZÁLEZ DE GÓMEZ, 2002, p. 28).

Destaque para a Conferência Intergovernamental para 0 Estabelecimento de um Sistema Mundial de Informação Científica, realizada de 4 a 8 de outubro de 1971 e promovida pela UNESCO, onde estavam presentes 84 Estados-Membros e 40 organizações internacionais, cujo propósito foi a criação e aprovação do programa UNISIST, que tinha como objetivo transferir e compartilhar a informação científica e técnica em nível mundial; promover as transformações necessárias no campo da informação científica e técnica; facilitar o acesso à informação; ajudar os países em desenvolvimento nas suas necessidades de informação; e estabelecer uma rede mundial de sistemas e serviços de informação (SILVA, 1994). 
Logo após, no período de 23 a 25 de setembro de 1974, em Paris, a UNESCO realizou outra importante conferência, cujos objetivos eram formular recomendações sobre a integração dos programas nacionais de documentação, bibliotecas e arquivos aos planos de educação, ciência, cultura, economia, comunicação e administração pública, a fim de contribuir com o progresso social e o desenvolvimento econômico dos países (SILVA, 1994).

Tais discussões trataram do planejamento integrado de infraestruturas nacionais de documentação, bibliotecas e arquivos; aplicação das tecnologias no desenvolvimento desses serviços; e formação de recursos humanos para a administração dos serviços, resultando em medidas e recomendações para implementação em vários países. Ressalta-se que esse evento contribuiu para a formação do conceito National Information System (NATIS), que representava o planejamento global das infraestruturas nacionais de informação, englobando os serviços de documentação, bibliotecas e arquivos (SILVA, 1994). É fato que tais ações influenciaram e estimularam políticas em alguns países, inclusive no Brasil.

No Brasil, destacam-se vários fatos e ações que foram configurando uma Política Nacional de Informação, como por exemplo, a criação de: institutos e centros de pesquisa; programas direcionados à tecnologia da informação e comunicação; portais; bibliotecas digitais e virtuais; cursos de graduação e de pós-graduação em Biblioteconomia e Documentação e Ciência da Informação; sistemas de informação; programas governamentais para incentivo à organização, ao armazenamento e à divulgação de acervos documentais; financiamento de projetos para o desenvolvimento científico e tecnológico; lançamento de periódicos; banco de dados; e etc. (GONZÁLEZ DE GÓMEZ; CANONGIA, 2001; PINHEIRO; LOUREIRO, 1995).

Os fatos relacionados à criação de sociedades e periódicos científicos e à realização de eventos na Ciência e na Cultura estão imbricados no tema estudado.

É oportuna a citação de Aun (1999, p. 5), quando afirma que "a construção de uma Política de Informação, no seu sentido mais amplo, é sem sombra de dúvidas um desafio para todos os Estados", pois se percebe, que durante décadas, foram concentrados esforços direcionados ao estabelecimento de infraestrutura, de tecnologia de informação, à criação de institutos de pesquisas, centros de informação e bibliotecas universitárias, de periódicos em Ciência da Informação e de linhas específicas de financiamento de projetos de pesquisa em ICT, para a formulação e implementação de Políticas de ICT.

No Brasil, uma importante ação para uma Política Nacional de Informação foi a criação de uma Comissão de Informação em Ciência e Tecnologia (CICT), no âmbito do III Plano Básico de Desenvolvimento Científico e Tecnológico (III PBDCT), sendo um dos objetivos a elaboração do documento denominado Ação Programada em Ciência e Tecnologia Informação em Ciência e Tecnologia. 
Esse documento foi elaborado a partir da identificação de sete áreas e da definição de grupos de trabalhos indicados pelas instituições participantes da Comissão de Informação em Ciência e Tecnologia e especialistas em ICT, a fim de identificar problemas e possíveis soluções dos tópicos: geração de documentos primários; formação e desenvolvimento de coleções; automação de bibliotecas; bases de dados bibliográficas; difusão e uso da informação; recursos humanos; e assuntos internacionais relacionados à informação científica e tecnológica, tendo sido submetido e aprovado pela CICT, ao final do processo (Conselho Nacional de Desenvolvimento Científico e Tecnológico - CNPQ, 1984).

González de Gómez (2002, p. 28) afirma que "apesar de muitos e importantes esforços, a formulação das Políticas de Informação não consegue o sucesso esperado nos países em desenvolvimento". Os programas e as instituições devem manter uma visão prospectiva em relação aos diversos interesses acerca da informação, a fim de que as ações e estratégias possam ser transformadas, evitando-se o recomeço. Pinheiro e Loureiro (2006, p.13?) comentam "nada surge do nada nem é absolutamente original, pois sempre há uma idéia ou um trabalho precedente, fundador do novo, a partir do antigo, transmutado".

Aun (1999) relata que, durante algumas entrevistas realizadas para sua pesquisa sobre a construção de uma Política Nacional e Supranacional de Informação, foi comentado que a partir de 1986 as instituições administrativas francesas responsáveis pela definição, pelo aconselhamento e pela implementação de Políticas de Informação, junto ao governo, foram desaparecendo. Ressalta-se que um dos entrevistados era Yves Le Coadic, pesquisador reconhecido na Ciência da informação.

Outro momento que se considera como 'divisor de águas', no que tange às ações para uma Política de Informação, foi o Programa Sociedade da Informação no Brasil, cujo objetivo é:

Integrar, coordenar e fomentar ações para a utilização de tecnologias de informação e comunicação, de forma a contribuir para a inclusão social de todos os brasileiros na nova sociedade e, ao mesmo tempo, contribuir para que a economia do País tenha condições de competir no mercado global (TAKAHASHI, 2000. p. 11).

As expectativas geradas na Sociedade da Informação impulsionaram segmentos da sociedade, pois o conjunto de propostas apresentado no conhecido Livro Verde abrange: "ampliação do acesso, meios de conectividade, formação de recursos humanos, iniciativa à pesquisa e desenvolvimento de nossas aplicações" (TAKAHASHI, 2000, p. 5).

Ressaltamos que as ações do Programa que mais se destacaram foram da infraestrutura de informação. Concordamos com González de Gómez (2002) que o termo infraestrutura informacional, conceituado no Livro Verde, "introduz uma quebra paradigmática", pois: 
A relação entre política e informação deverá ser buscada em sua imersão nos domínios econômicos e tecnológicos, desde onde atua no plano implícito das micropolíticas ou através de figuras econômicas (GONZÁLEZ DE GÓMEZ, 2002, p. 30).

Isso por que:

Os ambientes de rede pela desativação das formas prévias de vinculação social e discursiva e desconexão dos contextos habituais das mensagens, nem sempre respondem aos critérios de valor e aos procedimentos de confiabilidade da informação, constituídos nos diferentes espaços sociais de práticas e interações comunicacionais (GONZÁLEZ DE GÓMEZ, 2002, p. 34).

O estabelecimento e implementação de uma Política de Informação é amplo e complexo, requerendo um esforço coordenado. (GONZÁLEZ DE GÓMEZ, 1999b).

No contexto de desenvolvimento deste artigo, referencia-se a citação de González de Gómez, (1999b, p. 59) a respeito de Política de Informação sob o ponto de vista do regime de informação, isto é:

Políticas de Informação quando, tratando-se de uma questão colocada num domínio coletivo de ação, existem conflitos entre as diferentes formulações de objetivos, planos, atores e recursos atribuídos às ações do domínio e em conseqüência, com respeito ao alcance, às prioridades e às metas das ações de informação, de modo tal que aqueles conflitos não poderiam ser equacionados ou resolvidos por meios técnicos ou instrumentais e requerem a reformulação deliberativa de princípios, fins e regras para a concretização de planos coletivos e coordenados de ação, ou a mudança das relações de força dos atores envolvidos.

Essa definição representa o contexto da Embrapa, pois ela gera informações variadas, isto é, de Genética à Ciência do solo, onde cada tipo de informação requer um olhar técnico e específico no que tange às normas, profissionais, processamento e disseminação.

\section{Metodologia e Procedimentos}

A metodologia aplicada foi um estudo de usuário, realizado com os pesquisadores de uma instituição de pesquisa científica no segmento da agricultura e pecuária, vinculada ao Governo Federal do Brasil - a Empresa Brasileira de Pesquisa Agropecuária - EMBRAPA.

Na realização deste estudo, utilizou-se a técnica do incidente crítico (FLANAGAN, 1973, p. 99) que:

É um conjunto de procedimentos para a coleta de observações diretas do comportamento humano, de modo a facilitar sua 
utilização potencial na solução de problemas práticos e no desenvolvimento de amplos princípios psicológicos, delineando também procedimentos para a coleta de incidentes observados que apresentem significação especial e para o encontro de critérios sistematicamente definidos.

Flanagan (1973, p. 100) esclarece que:

Incidente é qualquer atividade humana observável que seja suficientemente completa em si mesma para permitir inferências e previsões a respeito da pessoa que executa o ato. [O autor acrescenta que para o ser crítico,] um incidente deve ocorrer em uma situação onde o propósito ou intenção do ato pareça razoavelmente claro ao observador e onde suas conseqüências sejam suficientemente definidas para deixar poucas dúvidas no que se refere aos seus efeitos.

A pesquisa foi realizada na Embrapa Solos, localizada no bairro do Jardim Botânico, no município do Rio de Janeiro, contando com a participação dos pesquisadores da Unidade. Esta pertence à Embrapa, instituição brasileira de P\&D, constituída por pesquisadores, bibliotecários, cientistas da informação e profissionais da informação, que têm a responsabilidade social no atendimento das necessidades da sociedade e respectivo benefício. A Unidade onde foi realizada a pesquisa é referência internacional em solos tropicais (EMBRAPA SOLOS, 2006).

$O$ objetivo foi obter relatos positivos e negativos ocorridos nos procedimentos ou na rotina adotados pelos pesquisadores da Embrapa Solos para produção científica.

As entrevistas foram gravadas, considerando-se os procedimentos da Técnica do Incidente Crítico (TIC).

Desse modo, os procedimentos foram assim definidos:

1. As entrevistas foram realizadas pela autora deste artigo;

2. A entrevista possibilitou relato de incidentes críticos no uso de recursos de informação disponíveis, como fonte para sua produção científica;

3. Na amostra foram estabelecidos critérios de seleção dos pesquisadores, conforme a seguir:

A Unidade pesquisada apresentava características de desenvolvimento de pesquisa científica e de prestação de serviços. Para obter-se uma homogeneidade do grupo a ser pesquisado foram considerados pesquisadores com titulação de Doutorado ou PósDoutorado, em exercício de suas funções;

Foram selecionados pesquisadores com uma trajetória de pesquisa registrada na Plataforma do Currículo Lattes, de responsabilidade do Conselho Nacional de Pesquisa Científica - CNPq, com atualização em 2006 e que fossem líderes ou membros de Projetos de Pesquisa da Embrapa Solos; 
Dos 57 (cinquenta e sete) pesquisadores com nível de Graduação, Mestrado, Doutorado e Pós-Doutorado lotados na Embrapa Solos, 12 (doze) pesquisadores atenderam aos critérios.

4. Roteiro e termos utilizados durante as entrevistas.

Segundo Pinheiro (2006), alguns termos técnicos na Ciência da Informação são originados por traduções equivocadas e isso é bem retratado quando nos referimos aos termos "fontes de informação" e "recursos de informação". O termo "recurso de informação" apresenta uma visão ampla no estudo de usuários. Assim, utilizamos o termo "fonte de informação", pois é o termo mais utilizado no cotidiano do corpo científico da Embrapa Solos.

Procedimentos adotados durante as entrevistas:

a- Entregue à Chefia da Embrapa Solos e pesquisadores entrevistados, folder explicativo da pesquisa;

b- Roteiro preestabelecido, contendo nome do pesquisador, área de atuação, projetos liderados e perguntas;

c- Entrevistas autorizadas previamente, em documento específico, pelo Chefe Geral da Unidade;

d- Entrevistas realizadas nas instalações da Embrapa Solos no Rio de Janeiro, agendadas e cada uma só pode ser remarcada uma vez;

e- Entrevistados autorizaram, em documento específico, a divulgação do conteúdo das entrevistas no âmbito deste artigo;

f- Na entrevista, a autora baseou-se nos critérios e termos definidos previamente, caso o entrevistado tivesse dificuldade em recordar algum incidente, pois segundo Kremer (1980), o mais importante nessa técnica é obter relatos reais da rotina do entrevistado com detalhes.

g- Considerando que as entrevistas foram realizadas pela autora e bibliotecária da Embrapa Solos, Kremer (1980) alerta que os entrevistados podem fornecer à entrevistadora respostas que eles julguem que a mesma deseja ouvir, deixando de relatarem a utilização de outras fontes de informação. Ao realizar a entrevista, a entrevistadora utilizou informações referentes à caracterização dos pesquisadores quanto à sua atuação em projetos e respectivas atividades na Embrapa Solos, tendo como base a Plataforma do Currículo Lattes - CNPq;

h- A primeira entrevista foi considerada pré-teste, a fim de identificar e efetuar possíveis correções no decorrer das demais;

i- Os relatos obtidos durante as entrevistas foram transcritos segundo Heinisch (2003) e Chalaça (2006), estruturados e os resultados analisados.conhecimento obtido, após a revisão de literatura, permitiu uma análise das formações da instituição pesquisada sob o enfoque do Regime de Informação, bem como o mapeamento das iniciativas, normas ou diretrizes para uma Política de Gestão da Informação, obtendo várias contribuições para as futuras políticas das unidades da Embrapa.

\section{Subsídios para uma política de gestão da informação: considerações}


O mapa teórico da Ciência da Informação, os métodos e as orientações esclarecedoras identificaram elementos do Regime de Informação da Embrapa e da Embrapa Solos, já instituídos, mas não revelados; investigaram o uso de fontes de informação no processo de produção científica dos pesquisadores e apresentaram os resultados como subsídio para uma Política de Gestão da Informação. Ao se pesquisar uma Política de Gestão da Informação devem ser ressaltadas as demandas e expectativas da sociedade, mercado nacional e internacional e políticas de governo; no âmbito das empresas, as demandas das políticas internas de informação, comunicação, propriedade intelectual, negócios, transferência de tecnologia, responsabilidade social, diretrizes, normas e regulamentos específicos para o funcionamento propriamente dito da instituição.

FIGURA 1 - Representação Gráfica do Regime de Informação da Embrapa. Fonte: Dados da pesquisa.

Sob o ponto de vista do Regime de Informação e estando presentes em um mesmo ambiente os atores sociais, representados, nesta pesquisa, pelos pesquisadores da Embrapa Solos, uma Política de Gestão da Informação permite que se identifiquem os pontos de relação e interseção com as demais políticas ou diretrizes da Embrapa e a política de acesso e disponibilização das informações geradas no âmbito dos projetos e pesquisas, resguardando os direitos autorais do autor. 
Considerando a formulação de Política de Gestão da Informação à luz do Regime de Informação, concordamos com a proposição feita por Unger (2006), quando revelou que existe a perspectiva do regime de traduz-

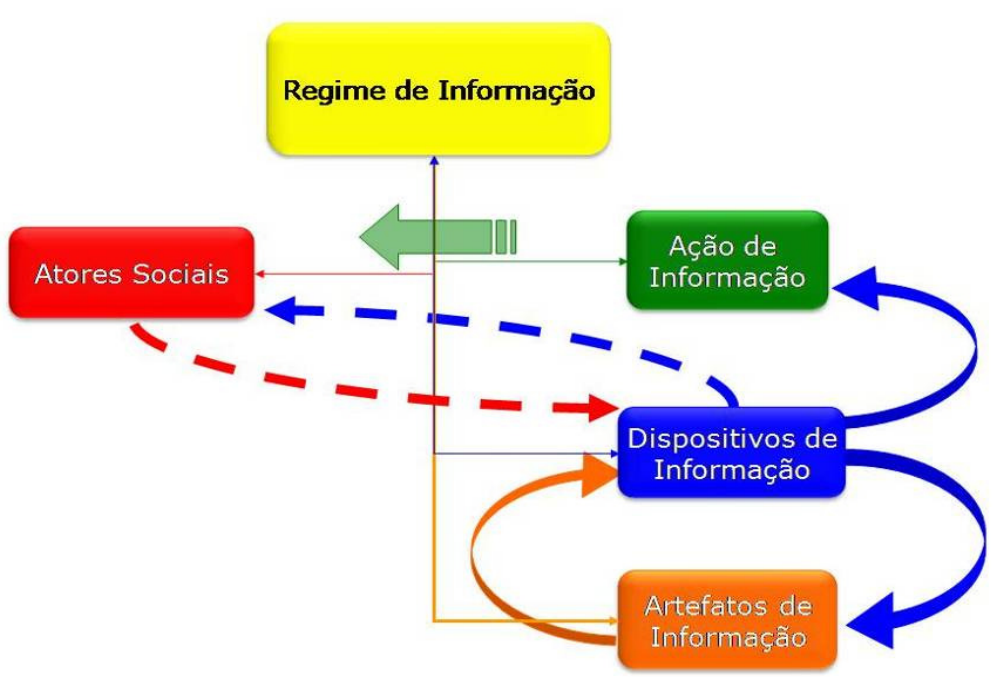
informação se como

oportunidade e desafio aos gestores da informação. Será necessária, na discussão e formulação de uma política, a participação de analistas de sistemas, comunicólogos, arquivistas, administradores, pesquisadores, etc.]

Cabe ressaltar que o regime de informação representado (FIG. 1) é refletido nas demais Unidades de Pesquisa, onde cada uma pode apresentar características, comportamentos, liderança e atuação conforme o ambiente em que está inserida.

Imbuídas do conceito de regime de informação dos seus componentes, sob o ponto de vista de uma Política de Gestão da Informação em C\&T, realizamos uma leitura transversal das políticas e demais documentos a respeito do tema na instituição e na Unidade pesquisada, e mapeamos cada um dos componentes do Regime da Informação, representados pelas FIG. 2, 3, 4, 5, configurando assim a "Identidade do Regime de Informação da Embrapa".

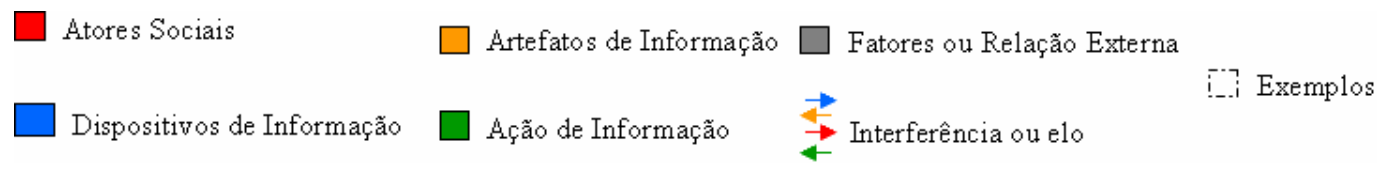

Utilizamos cores, objetos, setas e linhas na representação dos componentes do Regime de Informação e suas relações, de acordo com a legenda a seguir (legenda de representação do Regime de Informação e componentes):

- Atores Sociais: 


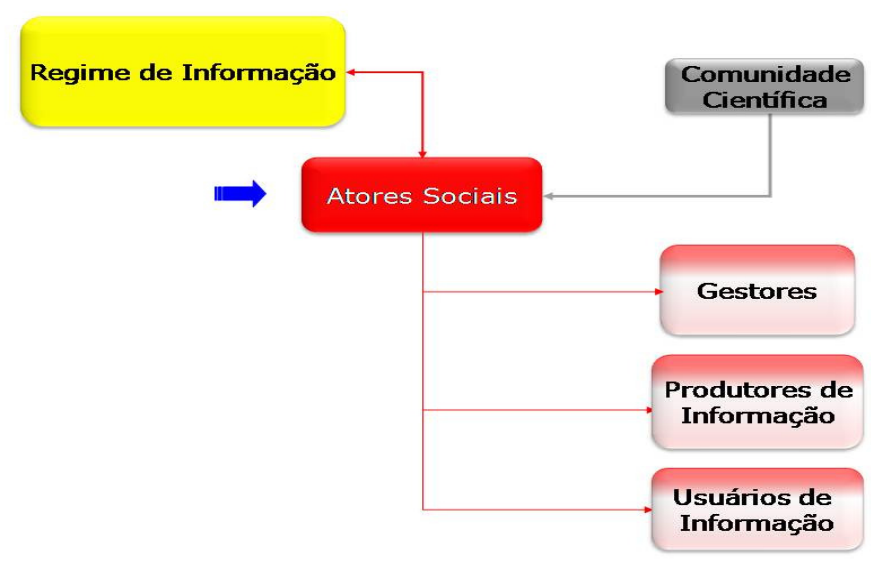

FIGURA 2 - Atores Sociais do Regime de Informação da Embrapa

Fonte: Dados da pesquisa.

Atores sociais identificados em uma Política de Gestão da Informação interna.

Dispositivos de Informação:

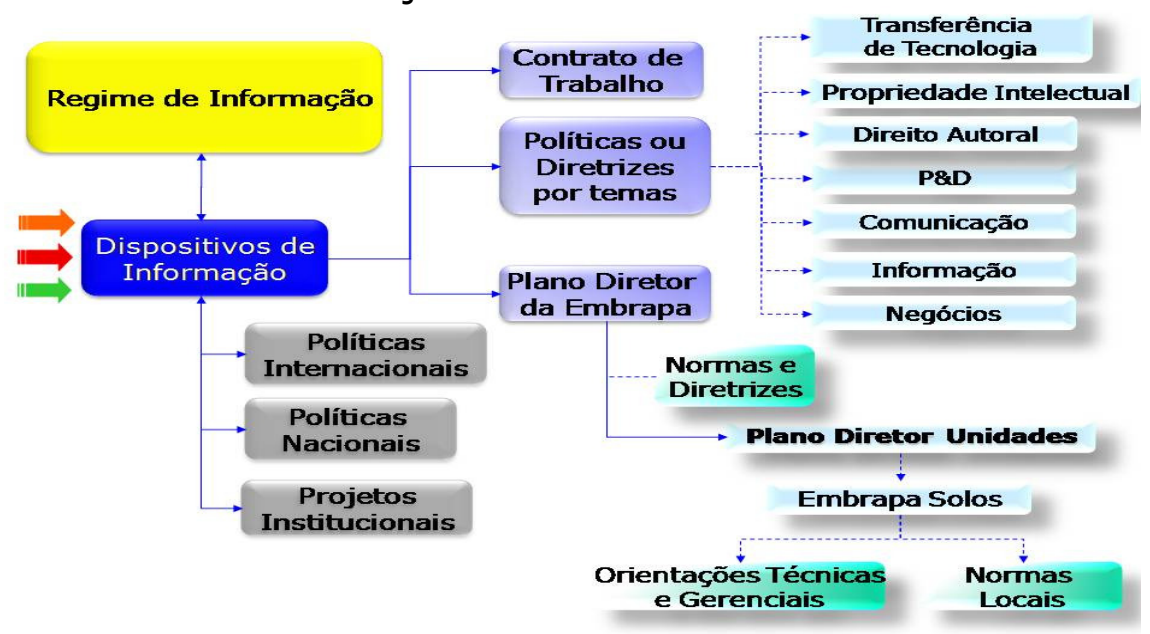

FIGURA 3 - Dispositivos de Informação na Embrapa

Fonte: Dados da pesquisa.

Assim como em atores sociais, nos dispositivos de informação podem ocorrer alterações ou relações, desde que modificados o ambiente ou o tema analisado.

Artefatos de Informação: 


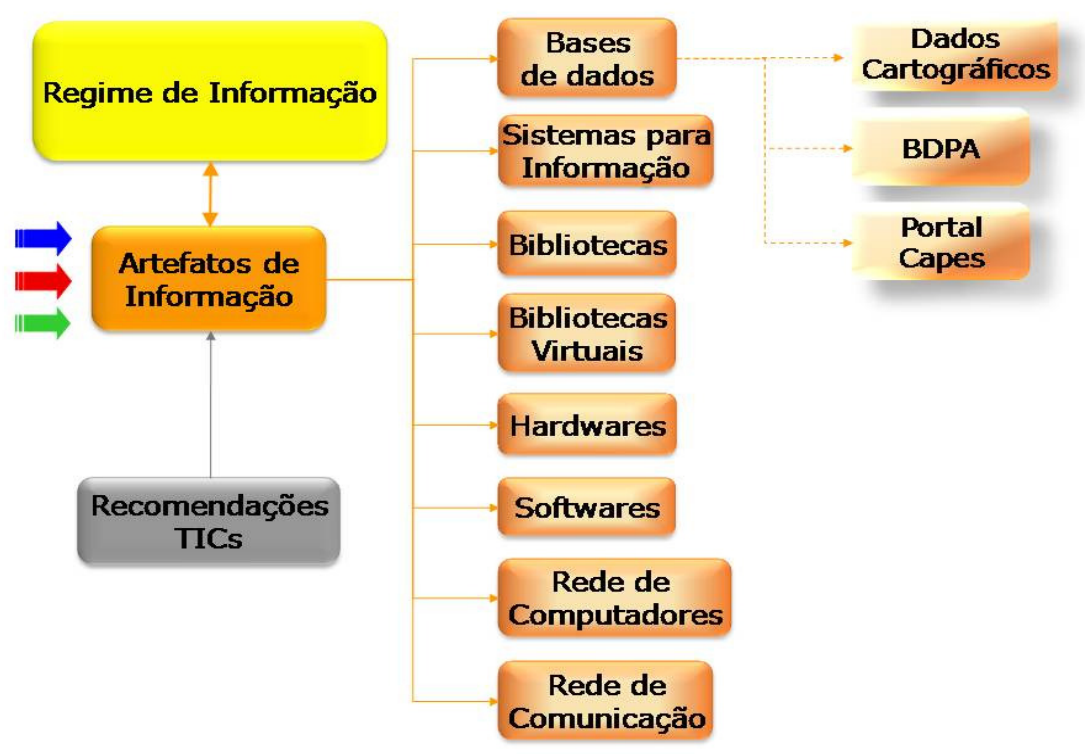

Figura 4 - Artefatos de Informação da Embrapa

Fonte: Dados da pesquisa.

Nos artefatos de informação foram identificadas normas, diretrizes e políticas externas que denominamos como "Recomendações TICs", as quais têm sido adotadas por essa instituição.

Ação de Informação:

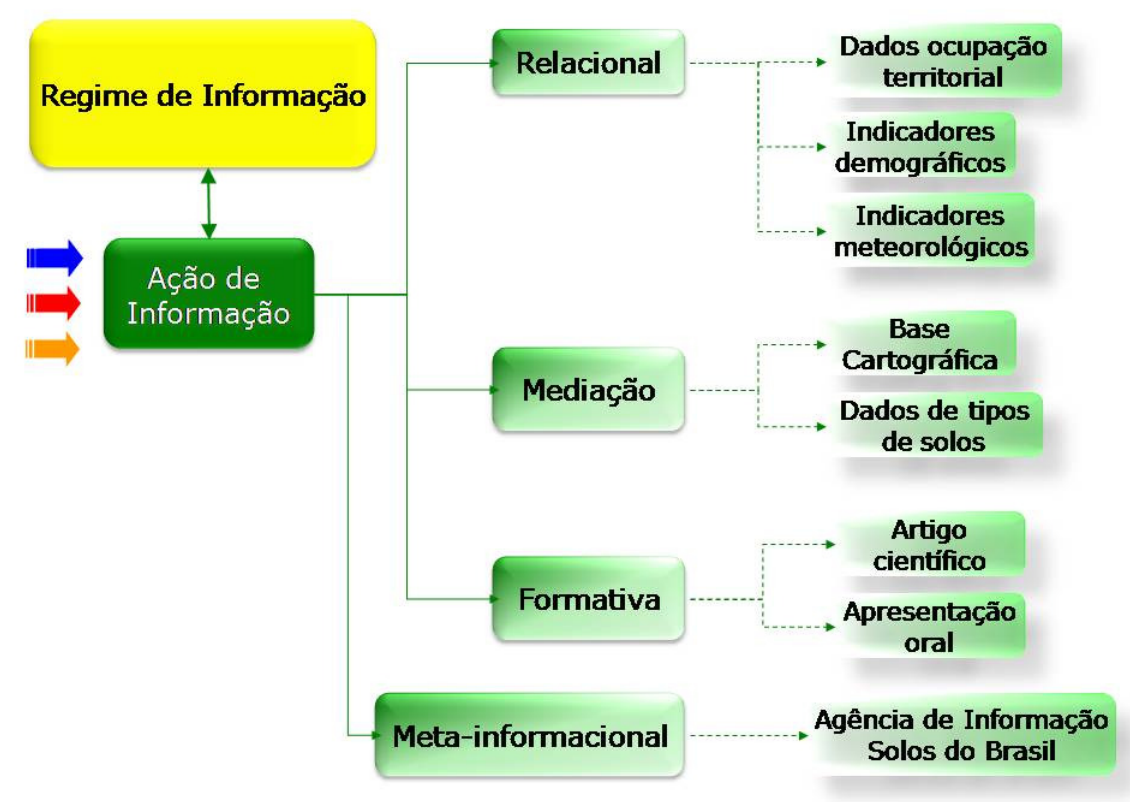

FIGURA 5 - Ação de Informação da Embrapa

Fonte: Dados da pesquisa.

O componente "Ação de Informação" é o ponto "nevrálgico" da eficiência de uma Política de Gestão da Informação. No momento em que os usuários buscam a informação serão percebidas questões relacionadas 
à compatibilidade das TICs, normas, acessibilidade, etc. Enfatizamos que no processo de Gestão da Informação, o foco nas necessidades e expectativas dos Atores Sociais deve ser mantido. Com base nas informações sobre a Embrapa e a Unidade pesquisada, essa instituição apresenta todos os componentes de um Regime de Informação, que pode ser retratado conforme exposto na FIG. 6.

Não se trata de uma análise sob o posto de vista da divulgação científica e sim da disseminação da informação, em ambiente interno. Pois, segundo Pinheiro (2003), a comunicação científica, que trata da comunicação entre cientistas, deve ser analisada e estudada segundo as especificidades e padrões dos produtores da informação, canais e o público ou segmento a que se destinam.

Sendo assim, o Regime de Informação da Embrapa Solos é configurado, nesta pesquisa, conforme a figura (FIG. 6), a seguir:

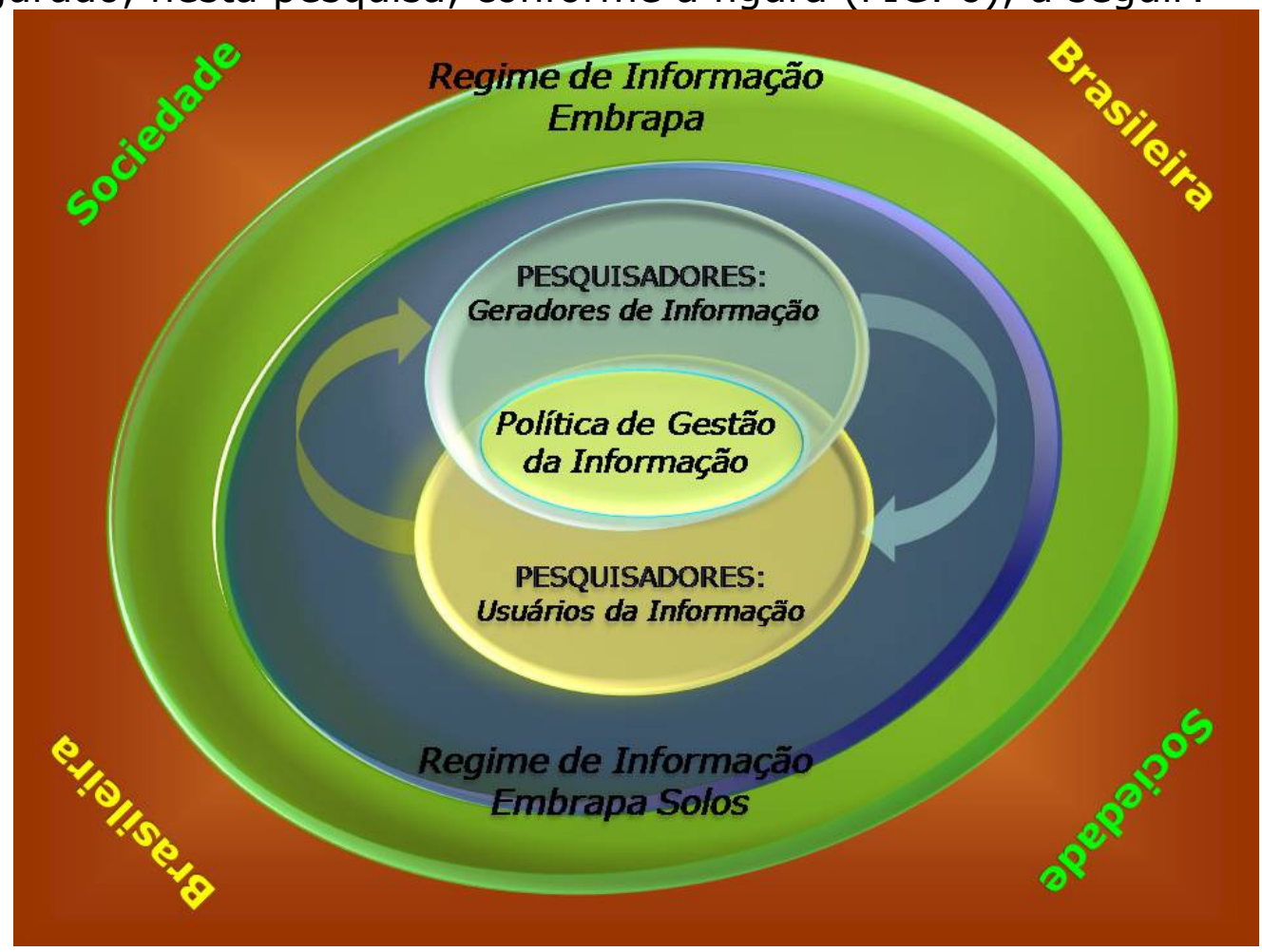

FIGURA 6 - Regime de Informação da Embrapa Solos

Fonte: Dados da pesquisa.

A partir da FIG. 6, percebe-se que a Gestão da Informação pode ser um ponto de mediação sob o ponto de vista do Regime de Informação para uma Política de Gestão da Informação, em que estão presentes, em um mesmo ambiente, os atores sociais, representados nesta pesquisa pelos pesquisadores da Embrapa Solos.

Tendo em vista que a Embrapa é uma instituição brasileira de P\&D e, assim, teria a responsabilidade de estabelecer políticas com o propósito de aperfeiçoar processos que tratam da informação, com vistas ao atendimento dos seus usuários ou público em geral, observamos que, na perspectiva do Regime de Informação e dos seus componentes, é possível 
obter uma visão dos recursos informacionais, tecnológicos, humanos e normativos em uma empresa de $P \& D$, no que se refere à Gestão da Informação. Os fluxogramas desses componentes e suas mútuas relações no regime de informação na Embrapa Solos possivelmente fornecerão subsídios para a discussão de uma Política de Gestão da Informação em Ciência e Tecnologia, na respectiva Unidade de Pesquisa.

Percebemos a necessidade de uma avaliação por parte dos gestores da Embrapa em relação aos seus instrumentos organizacionais, tendo como horizonte a informação em ciência e tecnologia, face às tendências mundiais de acesso livre à informação.

A FIG. 7, a seguir, exemplifica o processo pelo qual a informação gerada no âmbito dos projetos de pesquisa deverá percorrer no contexto de uma Política de Gestão da Informação, com base no Regime de Informação. Os itens descritos contemplam os componentes do Regime de Informação da Embrapa Solos.

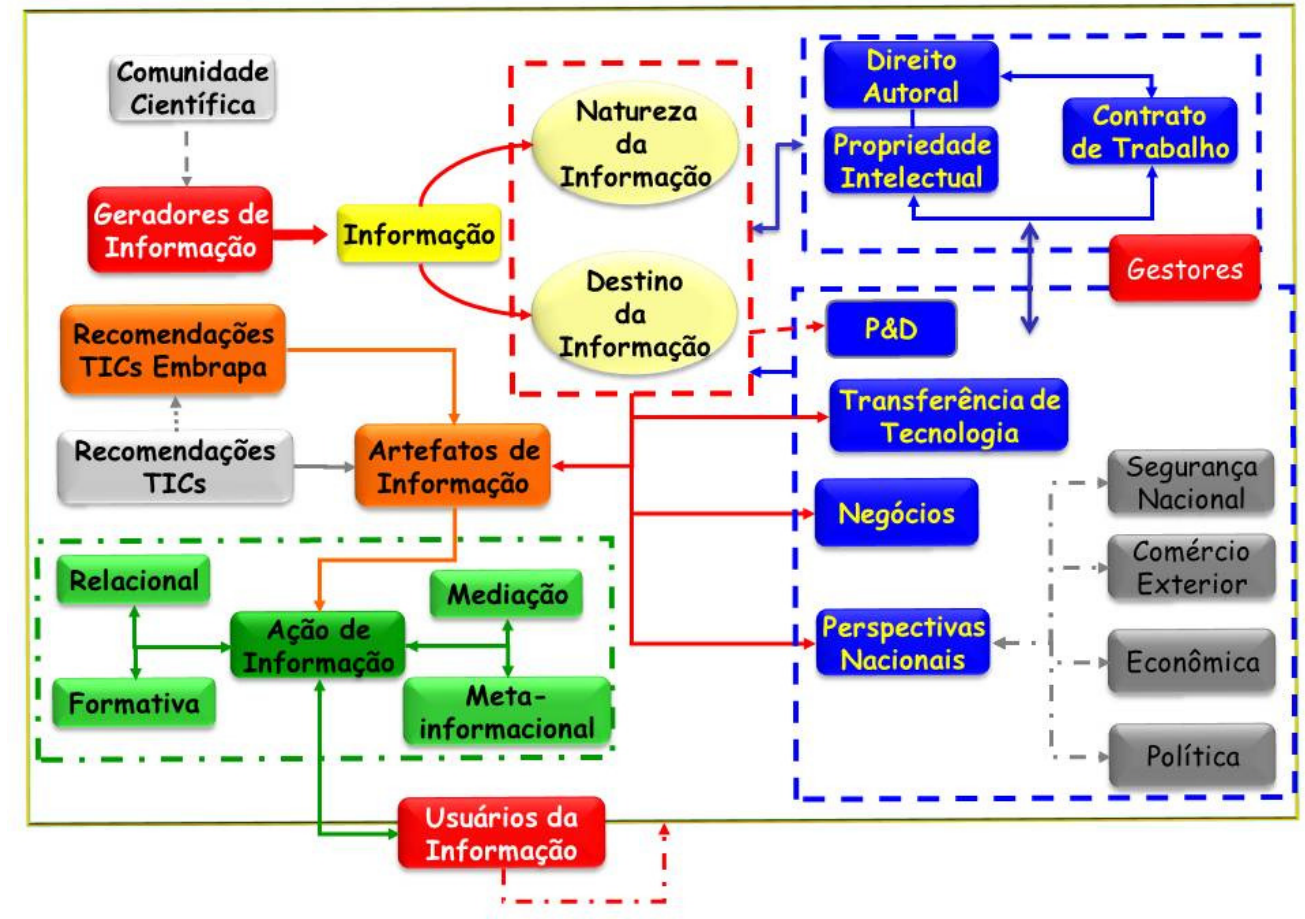

Figura 7 - Ação de uma Política de Gestão da Informação à luz do Regime de Informação na Embrapa

Fonte: Dados da pesquisa.

As cores utilizadas no diagrama foram baseadas na Legenda de representação do Regime de Informação e componentes apresentadas anteriormente.

Na FIG. 7, são demonstradas a ambiência, as relações e interrelações dos componentes do regime de informação.

A partir da informação gerada no âmbito dos projetos de pesquisa pelos pesquisadores é necessário que se tenha uma perspectiva inicial da natureza da informação a ser gerada, bem como o seu destino. 
Estabelecidos a natureza e o destino da informação, em consonância com as Políticas de P\&D, Transferência de Tecnologia, Negócios e as perspectivas e demandas de e para a instituição, faz-se necessário uma releitura das orientações e normas referente à Propriedade Intelectual, ao Direito Autoral, bem como suas relações e inter-relações com o contrato de trabalho dos geradores da informação.

Percebe-se a atuação dos Gestores da Instituição face aos interesses não só dos geradores da informação e da instituição, como também do Governo Brasileiro, principalmente, se a informação gerada tiver algum impacto em questões econômicas, sociais, políticas, internacionais ou de segurança nacional.

Definidas as questões quanto à natureza da informação e os dispositivos, a etapa seguinte refere-se à definição dos modos tecnológicos e materiais de armazenagem, processamento e de transmissão da informação. Ressalta-se que, nessa etapa, existem normas ou Recomendações, tanto internas quanto externas, referente às Tecnologias de Informação e Comunicação (TICs), que devem ser atendidas.

Percorridas as etapas anteriores, é na Ação de Informação que a Informação em C\&T atinge o seu propósito de interação com os Usuários da Informação, na ação de informação relacional, mediação, formativa ou meta-informacional. O conjunto das decisões iniciais, quanto aos demais componentes do Regime de Informação e de suas regras, interferirá positivamente no destino da informação gerada no início do processo e na interação com o usuário.

Sendo assim, percebe-se, a partir dos dados empíricos, a importância de uma Política de Gestão da Informação em Ciência e Tecnologia para os pesquisadores da Embrapa Solos, onde estes reconhecem, implicitamente, sua atuação nas ações de uma política, mas ressaltam que ainda existe a necessidade de definições no cenário tecnológico, organizacional, de comunicação e das competências informacionais para que, de fato, esta Política de Gestão da Informação seja efetiva frente às expectativas atuais do corpo científico da Embrapa e, também, das expectativas futuras da Sociedade.

As mútuas relações em uma Política de Gestão da Informação, representadas pelas setas coloridas e bidirecionais, refletem a necessidade de uma sintonia e sincronia entre todos os seus componentes, ou seja, geradores de informação, gestores, usuários da informação; políticas internas e externas, normas, diretrizes, contrato de trabalho, demandas e perspectivas; softwares, hardwares, redes de comunicação, bibliotecas e portais. Porém, a natureza e o destino da informação que se pretende gerenciar é um fator norteador e determinante para uma Política de Gestão da Informação.

\section{Referências}


AUN, M. P. A construção de políticas nacional e supranacional de informação: desafio para os Estados nacionais e blocos regionais. Ciência da Informação, Brasília, v. 28, n. 2, p. 1-9, 1999.

BRAMAN, S. The emergent global information policy regime. Houndsmills,UK: Palgrave Macmillan, 2004.

CIANCONI, R. Gestão da informação na sociedade do conhecimento. Brasília, DF: SENAI/DN, 1999.

COLLINS, H. M.; KUSH, M. The shape of actions what humans and machines can do. Cambridge, Mass.: MIT Press, 1999. p. 11-21 apud GONZÁLEZ DE GÓMEZ, M. N. Escopo e abrangência da Ciência da Informação e a Pós-Graduação na área: anotações para uma reflexão. Transinformação, Campinas, v. 15, n. 1, p. 31-43, jan./abr. 2003.

CHALAÇA, A. M. C. O tesouro de conhecimento da Maré: pessoas como fontes de informação. 45 f. 2006. Monografia (Graduação) - Universidade Federal do Estado do Rio de Janeiro, Rio de Janeiro, 2006.

CONSELHO NACIONAL DE DESENVOLVIMENTO CIENTÍFICO E TECNOLÓGICO (CNPq). Informação em Ciência e Tecnologia. Brasília, DF: CNPq, 1984. (Ação Programada em Ciência e Tecnologia; 29).

DAVENPORT, T. H. Ecologia da informação: por que só a tecnologia não basta para o sucesso na Era da Informação. São Paulo: Futura, 1998.

EMBRAPA SOLOS. II Plano diretor da Embrapa Solos, 2004-2007. Rio de Janeiro: Embrapa, 2005. Disponível em: <http://www.cnps.embrapa.br>. Acesso em: 5 out. 2006.

FERREIRA, A. B. H. Minidicionário da língua portuguesa. 3.ed. rev. amp. Rio de Janeiro: Nova Fronteira, 1993. $1 \mathrm{v}$.

FLANAGAN, J. C. A técnica do incidente crítico. Arquivos Brasileiros de Psicologia Aplicada, Rio de Janeiro, v. 25, n. 2, p. 99-141, abr./jun.1973.

FOUCAULT, M. O sujeito e o poder. In: DREYFUS, H.; RABINOW, P. Michel Foucault: uma trajetória filosófica: para além do estruturalismo e da hermenêutica. Rio de Janeiro: Forense Universitária, 1995. p. 231-249 apud WILKE, V. C. L.; JARDIM, J. M. Dispositivo de informação contemporâneo: considerações preliminares para uma arqueo-genealogia do horizonte informacional em nossa contemporaneidade. In: ENCONTRO NACIONAL DE PESQUISA EM CIÊNCIA DA INFORMAÇÃO, 7., 19-22 nov. 2006, Marília. Anais... Marília, SP: Ancib, 2006. 11 p. Disponível em: $<$ http://www.portalppgci.marilia.unesp.br/enancib/viewpaper.php?id=262 $>$. Acesso em: 20 de fev. 2008.

FROHMANN, B. Taking information policy beyond Information Science: applying the actor network theory for connectedness: information, systems, people, organizations. In: ANNUAL CONFERENCE FOR INFORMATION SCIENCE, 23., Alberta, 7-10 Jun. 1995. Alberta: Canadian Association for Information Science, 1995. Disponível em 
$<$ http://www.fims.uwo.ca/people/faculty/frohmann/actor.htm>

Acesso em: 10 out. 2006.

GONZÁLEZ DE GÓMEZ, M. N. Da organização do conhecimento às Políticas de Informação. INFORMARE - Cadernos do Programa de Pós-Graduação em Ciência da Informação, Rio de Janeiro, v. 2, n. 2, p. 58-66, jul./dez. 1996.

. Política e gestão da informação: novos rumos [editorial]. Ciência da Informação, Brasília, DF, v. 28, n. 2, 1 p., maio/ago. 1999a.

Da política de informação ao papel da informação na política contemporânea. Revista Internacional de Estudos Políticos, Rio de Janeiro, v. 1, n. 1, p. 57-93, abr. 1999b.

- O caráter seletivo das ações de informação. INFORMARE Cadernos do Programa de Pós-Graduação em Ciência da Informação, Rio de Janeiro, v. 5, n. 2, p. 7-30, jul./dez. 1999c.

- Escopo e abrangência da Ciência da Informação e a PósGraduação na área: anotações para uma reflexão. Transinformação, Campinas, v. 15, n. 1, p. 31-43, jan./abr. 2003.

GONZÁLEZ DE GÓMEZ, M. N.; CANONGIA, C. (Orgs.). Contribuição para políticas de ICT. Brasília, DF: IBICT, 2001.

INSTITUTE OF INFORMATION SCIENTISTS. Criteria for information science. Disponível em: <http://www.iis.org.uk/membership/ Criteria.html>. Acesso em: ago. 2001 apud MARCHIORI, P. Z. A ciência e a gestão da informação: compatibilidades no espaço profissional. Ciência da Informação, Brasília, DF, v. 31, n. 2, maio/ago. 2002. Disponível em: <www.scielo.br>. Acesso em: 24 mar. 2007.

JARDIM, J. M. Sistemas e políticas públicas de arquivos no Brasil. Niterói: EDUFF, 1995 apud GONZÁLEZ DE GÓMEZ, M. N. Novos cenários políticos para a informação. Ciência da Informação, Brasília, v. 31, n. 1, p. 27-40, jan./abr. 2002.

HEINISCH, L. M. M. Otimização da entrevista médica. 2003. 141 f. Tese (doutorado) - Universidade de Santa Catarina, Florianópolis, 2003.

KREMER, J. M. A técnica do incidente crítico = The critical incident technique. Revista da Escola de Biblioteconomia UFMG, Belo Horizonte, v. 9, n. 2, p. $165-176$, set. 1980

MARCHIORI, P. Z. A ciência e a gestão da informação: compatibilidades no espaço profissional. Ciência da Informação, Brasília, DF, v. 31, n. 2, maio/ago. 2002. Disponível em: <www.scielo.br>. Acesso em: 24 mar. 2007.

McGEE, J.; PRUSSAK, L. Gerenciamento estratégico da informação: aumente a competitividade e a eficiência de sua empresa utilizando a informação como uma ferramenta estratégica. 5.ed. Rio de Janeiro: Campus, 1994. (Série Gerenciamento da Informação). 
PEREIRA, M. N. F. Prefácio que esclarece o leitor a propósito do sonho de Otlet: aventura em tecnologia da informação e comunicação. In: PEREIRA, M. N. F.; PINHEIRO, L. V. R. (Org.) O sonho de Otlet: aventura em tecnologia da informação e comunicação. Rio de Janeiro, Brasília, DF: IBICT/DEP/DDI, 2000.

PINHEIRO, L. V. R. Comunidades científicas e infra-estrutura tecnológica no Brasil para uso de recursos eletrônicos de comunicação e informação na pesquisa. Ciência da Informação, Brasília, v. 32, n. 3, p. 62-73, set./dez. 2003.

PINHEIRO, L. V. R.; LOUREIRO, J. M. M. Traçados e limites da ciência da informação. Ciência da Informação, Brasília, v. 24, n. 1, p. 42-53, 1995.

PINHEIRO, L. V. R. Fontes ou recursos de informação: categorias e evolução conceitual. Pesquisa Brasileira em Ciência da Informação e Biblioteconomia, Rio de Janeiro, v. 1, n. 1, 2006. Editorial.

PINHEIRO, L. V. R., LOUREIRO, J. M. M. Políticas públicas de C\&T, ICT e de pós-graduação e o surgimento da ciência da informação no Brasil. In: CINFORM - ENCONTRO NACIONAL DE CIÊNCIA DA INFORMAÇÃO, 5., 2004, Salvador. Anais eletrônicos... Disponível em <http://www.cinform.ufba.br/v anais/frames.html>. Acesso em: 14 nov. 2006.

SARACEVIC, T. Ciência da informação: origem, evolução e relações. Perspectivas em Ciência da Informação, Belo Horizonte, v. 1, n. 1, p. 4162, jan./jun. 1996. ${ }^{5}$

SILVA, L. A. G. da. Políticas e programas de Informação e Documentação da UNESCO e fontes para seu estudo. Informação \& Sociedade: Estudos, João Pessoa, v. 4, n. 1, p. 68-84, jan./dez. 1994.

TAKAHASHI, T. (org.). Sociedade da Informação no Brasil: Livro Verde. Brasília, DF: Ministério da Ciência e Tecnologia, 2000. Disponível em: <http://www.mct.gov.br>. Acesso em: 18 out. 2006.

U.S.PRESIDENT'S SCIENCE AND ADVISORY COMMITEE. Science, government and information: the responsabilities of the technical community and the government in the transfer of information. Washington, D.C.: Government Printing Office, 1963. 52 p. (The "Weinberg Report") apud GONZÁLEZ DE GÓMEZ. Novos cenários políticos para a informação. Ciência da Informação, Brasília, v. 31, n. 1, p. 27-40, jan./abr. 2002.

UNGER, R. J. G. Regimes de informação na Sociedade da Informação: uma contribuição para a gestão da informação, 2006. 108 f. Dissertação (Mestrado) - Universidade Federal Fluminense, Instituto Brasileiro de Informação em Ciência e Tecnologia, Rio de Janeiro, 2006.

\footnotetext{
${ }^{5}$ Tradução do original SARACEVIC, T. Information science: origin, evolution and relations. In: VAKKARI, P.; CRONIN, B. Concepts of library and information science: historical, empirical na theoretical perspectives. Los Angeles, CA: Taylor Graham, 1992.
} 
WILKE, V. C. L.; JARDIM, J. M. Dispositivo de informação contemporâneo: considerações preliminares para uma arqueo-genealogia do horizonte informacional em nossa contemporaneidade. In: ENCONTRO NACIONAL DE PESQUISA EM CIÊNCIA DA INFORMAÇÃO, 7., 19-22 nov. 2006, Marília. Anais... Marília, SP: Ancib, 2006. 11 p. Disponível em: $<$ http://www.portalppgci. marilia.unesp.br/enancib/viewpaper.php?id=262 >. Acesso em: 20 de fev. 2008.

ZIMAN, J. Conhecimento público. Belo Horizonte: Itatiaia; São Paulo: Ed. da Universidade de São Paulo,1979. 164 p. (Coleção o homem e a ciência, v. 8). 